\title{
Aşağı Sakarya Nehri Su Kalitesinin Sulama Suyu Açısından Değerlendirilmesi
}

\author{
Çiğdem Özer ${ }^{1, *} \oplus$, Rabia Köklü² \\ ${ }^{1}$ Bitlis Eren Üniversitesi, Mühendislik- Mimarlık Fakültesi, Çevre Mühendisliği Bölümü, 13000, Bitlis. \\ ${ }^{2}$ Sakarya Üniversitesi, Mühendislik Fakültesi, Çevre Mühendisliği Bölümü, 54187, Sakarya.

\section{Özet}

Aşağı Sakarya Alt Havzası, Sakarya Nehrinin doğduğu noktadan itibaren maruz kaldi $\breve{l}$ sanayi faaliyetlerinin ve yerleșim yerlerinden kaynaklanan atıksuların, tarımsal ve kentsel yayılı kaynakların ve geçtiği jeolojik formasyonların etkisi altındadır. Tüm bu kirletici yüklerin etkisine răgmen geçtiği bölgelerde aynı zamanda tarımsal sulama maksadıyla da kullanılmaktadır. Bu nedenle, bu su kaynağının içme ve endüstriyel kullanımı yanında özellikle tarımsal amaçlı sürdürülebilir kullanımının önemi artmaktadır. Bu amaçla, çalı̧̧ma kapsamında Aşağı Sakarya Nehrinin tarımsal amaçlı sulama suyu bakımından kalitesi belirlenmiştir. Aşağ Sakarya Nehri üzerinde Devlet Su İsleri (DSI) tarafindan ișletilen 3 adet istasyona ait su kalite verilerine ait farkl fiziko-kimyasal özellikler farklı sulama suyu standartları açısından değerlendirilmiştir. Bu standartlar temelinde sulama suyu kalitesi, Elektriksel iletkenlik (EI)), ve Toplam Sertlik (TS) değerleri ile Schoeller Diyagramı, Sodyum Adsorbsiyon Oranı (SAR), Sodyum yüzdesi (\%Na), Magnezyum Oranı (MR), Potansiyel Tuzluluk (PS) ve Kelley indeksi (KI) gibi değerlendirme kriterleri kullanılarak yorumlanmıştır.

\section{$\underline{\text { Anahtar Sözcükler }}$}

Aşağı Sakarya Nehri, Sulama Suyu, Su Kalitesi

\section{Assessment of Lower Sakarya River Water Quality in Terms of Irrigation Water}

\begin{abstract}
The Lower Sakarya Sub-Basin is under the influence of the industrial activities and the wastewater from settlements, agricultural and urban run-off and the geological formations it has undergone since the birth of the Sakarya River. In spite of the effect of all these pollutant loads, it is also used for agricultural irrigation purposes. Therefore, the importance of sustainable use of this water resource for drinking and industrial use as well as for agricultural purposes is increasing. For this purpose, Lower Sakarya River quality of irrigation water for agricultural purposes has been determined. Different physical-chemical properties of water quality data belonging to 3 stations operated by State Hydraulic Works (DSI) on Sakarya River were evaluated in terms of national and international water quality standards. On the basis of these standards, irrigation water quality was interpreted by using evaluation criteria such as Electrical conductivity (EC), and Total Hardness (TH) values, Schoeller Diagram, Sodium Adsorption Rate (SAR), Sodium percentage (\% Na), Magnesium Ratio (MR), Potential Salinity (PS) and Kelley index (KI).
\end{abstract}

Keywords

Lower Sakarya River, Irrigation Water, Water Quality

\section{Giriş}

Su kaynakları endüstriyel ve tarımsal faaliyetler sonucu özellikle alıcı ortam olarak kullanılmaları nedeniyle son yıllarda kirlilik tehdidi ile karşı karşıya kalmaktadır. Sürdürülebilir bir su yönetimi ve bu kaynakların içme-sulama maksatlı kullanımı için su kütlelerinde meydana gelen fiziksel ve kimyasal değişimlerin sürekli izlenmesi ve değerlendirilmesi önem arz etmektedir.

Doğduğu noktadan itibaren birçok ilden geçen Sakarya Nehri, Aşağı Sakarya Alt Havzasına gelene kadar arıtma tesislerine sahip olmayan sanayi faaliyetlerinden ve yerleşim yerlerinden kaynaklanan atıksulardan, tarım faaliyetleri sonucunda oluşan yayılı kaynaklardan, kent içi küçük sanayilerden, yağmur sularının taşımış olduğu kirliliklerden ve geçtiği jeolojik formasyonlardan etkilenmektedir. Sakarya nehri tüm bu kirletici yüklerine rağmen aynı zamanda geçtiği bölgelerde çiftçiler tarafından sulama suyu olarak da kullanılmaktadır. DSİ Yukarı Sakarya Sulama Tesisi Geyve ve Pamukova İlçelerinin 7.900 hektar tarım arazisine Sakarya Nehrinden sulama suyu temin edilmekte ve bu tesis Geyve ve Pamukova Sulama Birlikleri tarafından işletilmektedir (URL-1 2016).

Sulanan tarım, kullanılabilir kalitede yeterli su kaynağına bağlıdır (Islam 2009). Tarımsal amaçlı su kalitesi de, suyun bitki kalitesi ve verimi üzerindeki etkisi ve toprak özelliklerine olan etkisine bağlı olarak belirlenir (Etteieb vd. 2015). 
Sulama suyu kalitesi bitki gelişimini doğrudan veya dolaylı olarak zehirlilik ve bitkilerin besin kullanımını önlemesi yoluyla etkilemektedir (Asri vd. 2010; Emre ve Sözbilir 2005). Özellikle, tarımsal maksatla kullanılan suların içeriğinde bulunan çözünmüş maddelerin neler olduğu ve bunların konsantrasyonu sulama suyunun kalitesini belirler. Sulama suyu analizleri ile su içinde bulunan tuzların toplam konsantrasyonu belirlendiği gibi önemli tuzların veya elementlerin miktarları da saptanır.

Su kullanımı için artan ihtiyaca bağlı olarak, ekili arazilerin sulanması için gerekli su, miktar ve kalite bakımından bozulmaktadır. Ayrıca, mahsul üretimi ve toprak kalitesi sulama için kullanılacak suyun kalitesi ile ilişkilidir (Etteieb vd. 2015). Çünkü sulama ile yetişen bitkiye etki eden önemli bir faktör toprağın kimyasal özellikleridir. Sulama suyu içeriğinde bulunan bileşiklerin bitkiye yararlı ya da yararsız hale geleceği de yine toprak özelliklerinin belirlediği bir durumdur. Dünyanın birçok bölgesinde yaygın olarak görülen tuzluluk artışıyla yılda 10 milyon hektar tarım arazisinin kaybedilmesi, toprak-su kalitesi etkileşim durumu için dramatik bir örnektir (Numaan 2011). Çünkü bilinçsiz ve aşırı sulama, su kaynaklarının kuruma tehlikesinin yanında, tarımsal amaçlı kullanılan topraklarda da tuzluluk tehlikesi yaratmaktadır. Bu nedenle sulama suyu kalitesi belirlenirken toplam tuz konsantrasyonu, sodyum yüzdesi ve diğer katyonlarla ilişkileri, kalsiyum ve magnezyum miktarı ve bunun yanında bitkilere önemli etkisi olan Bor konsantrasyonu da dikkate alınmaktadır.

Kalite kriterleri olarak da ülkemizde genel olarak ABD Tuzluluk Laboratuvarı tarafından geliştirilen grafik sistemi kullanılmaktadır. Bunun yanında 2014 yılında Orman ve Su İşleri Bakanlığı tarafından sulama suyu olarak kullanılan su kaynaklarının korunması, iyileştirilmesi ve sulama suyu kriterlerinin belirlenmesi amacıyla Sulama Sularının Kalitesi ve Kullanılmış Suların Yeniden Kullanılması Hakkında Yönetmelik Taslağı hazırlanmıştır. Yönetmelik taslağının EK 1 kısmında SAR, Eİ, TÇM (Toplam Çözünmüş madde), Na, Cl, B (Bor) gibi parametreleri içeren sulama suyu kriterleri, iz element konsantrasyonları, mikrobiyolojik kalite gibi sulama suyu kalite değerlendirmelerine yer verilmiştir. Yönetmelik hala taslak durumunda olduğu için bu çalışmada değerlendirmeye alınmamıştır.

$\mathrm{Bu}$ çalışmada, Sakarya Nehrinin tarımsal amaçlı sulama suyu bakımından kalitesinin belirlenmesi ve değerlendirilmesi amaçlanmıştır. Bu amaçla, Sakarya Nehri üzerinde DSİ tarafından belirlenen 3 adet istasyona ait su kalite verileri, sulama suyu kalitesi açısından Elektriksel iletkenlik (EI), ve Toplam Sertlik (TS) değerleri ile Sodyum Adsorbsiyon Oranı (SAR), Sodyum yüzdesi (\%Na), Magnezyum Oranı (MR), Potansiyel Tuzluluk (PS) ve Kelley indeksi (KI) gibi parametreler kullanılarak değerlendirilmiştir.

\section{Materyal Yöntem}

\section{1. Çalışma Alanı}

Marmara Bölgesinin en önemli tatlı su kaynaklarından biri olan Sakarya Nehri Havzası 58160 km²'lik drenaj alanı ve 824 km'lik uzunluğu ile Türkiye'nin en önemli ve büyük havzalarından biridir. Nehrin 159,5 km'lik kısmı Sakarya İl sınırları içinden, Adapazarı şehir merkezinin 4 km doğusundan geçmektedir. Sakarya Nehri, Mudurnu Çayını ve Sapanca Gölü'nün aşırı suyunu boşaltan Çark suyunu aldıktan sonra Karasu İlçe Merkezi'nden Karadeniz'e dökülür (Morkoyunlu 2016).

Sakarya Havzası'nda yoğun sanayi, teknolojik ve tarımsal gelişmeler ile sürekli artan nüfus yoğun kirlenmelere neden olmaktadır. Türkiye'de Aşağı Sakarya Alt Havzası endüstriyel faaliyetin en yoğun olduğu havzalardan biridir. Sakarya Nehri, kendisine bağlanan kolları ve ana kol üzerindeki tüm yerleşimlere ait arıtılmış-arıtılmamış endüstriyel ve evsel atıksular ile tarımsal faaliyetler sebebiyle kirlenmiş bir halde Aşağı Sakarya Alt Havzası'na ulaşmaktadır (Dündar 2008).

Bölge iklimi 1lık ve yağmurludur. Bölgede yıllık ortalama en yüksek sicaklık $19,87^{\circ} \mathrm{C}$, ortalama en düşük sıcaklık $9,94{ }^{\circ} \mathrm{C}$ ve ortalama sicaklık $14,4{ }^{\circ} \mathrm{C}$ 'dir. Aylık toplam yağış miktarı ortalamas $167,1 \mathrm{~kg} / \mathrm{m}^{2}$ ve yıllık ortalama yağış $835 \mathrm{~mm}$ 'dir (MGM).

Aşağı Sakarya Havzasında yer alan Adapazarı ili, eski bir göl yatağı kenarında kuruludur. Şehrin kuzeyde yer alan kısmı Sakarya Nehri ve kollarıyla taşınarak derin göl çökelleri üzerinde birikmiş kuvaterner, alüvyon zemin üzerindedir. Adapazarı, Akyazı ve Hendek ovalarını oluşturan birim, tutturulmamış kum, silt, kil ve çakıldan meydana gelmektedir (Yaykıran 2016). Sakarya nehri etrafından yoğun hayvancılık ve tarımsal faaliyetler yapılmaktadır. Arazinin bir kısmı düz ve taban arazisidir. Toprak yapısı her türlü tarıma elverişlidir. Tarımda pancar, mısır, tütün ve buğday yetiştirilmektedir.

\subsection{Yöntem}

Çalışmada kullanılan veriler, Aşağı Sakarya Nehri üzerinde Pamukova (İS1), Doğançay (İS2) ve Adatepe (İS3) isimli örnekleme istasyonları bulunan Devlet Su İşleri Genel Müdürlüğü’nden temin edilmiştir (Şekil 1). İstasyonlarda ölçümü yapılan parametrelerden elektriksel iletkenlik (Eİ, mohm/cm), Toplam Sertlik (TS, mg L $\left.{ }^{-1}\right)$, Klorür $\left(\mathrm{Cl}^{-}, \mathrm{mg} \mathrm{L}^{-1}\right)$, Sülfat $\left(\mathrm{SO}_{4}{ }^{2-}, \mathrm{mg} \mathrm{L}^{-1}\right)$, Sodyum $\left(\mathrm{Na}^{+}, \mathrm{mg} \mathrm{L}{ }^{-1}\right)$, Potasyum $\left(\mathrm{K}^{+}, \mathrm{mg} \mathrm{L}{ }^{-1}\right)$, Kalsiyum $\left(\mathrm{Ca}^{2+}, \mathrm{mg} \mathrm{L}^{-1}\right)$, Magnezyum $\left(\mathrm{Mg}^{2+}, \mathrm{mg} \mathrm{L}^{-1}\right)$ konsantrasyonları sulama suyu kriterlerini belirlemek için kullanılan indeksleri hesaplamak üzere kullanılmıştır. Parametrelerden yalnızca TS değeri mg/L olarak kullanılmış, diğer parametrelerin konsantrasyonları meq/l birimine dönüştürülerek eşitlikler hesaplanmıştır. 
Konsantrasyonlar, Elektriksel iletkenlik (EI), ve Toplam Sertlik (TS) değerleri ile Schoeller logaritmik diyagramı, Sodyum Adsorbsiyon Oranı (SAR), Sodyum yüzdesi (\% Na), Magnezyum Oranı (MR), Potansiyel Tuzluluk (PS) ve Kelley indeksi (KI) gibi sulama indeksleri kullanılarak hesaplanmış ve yorumlanmıştır. Yöntemlere ait sulama suyu sinıflandırmaları Tablo 1'de verilmektedir.

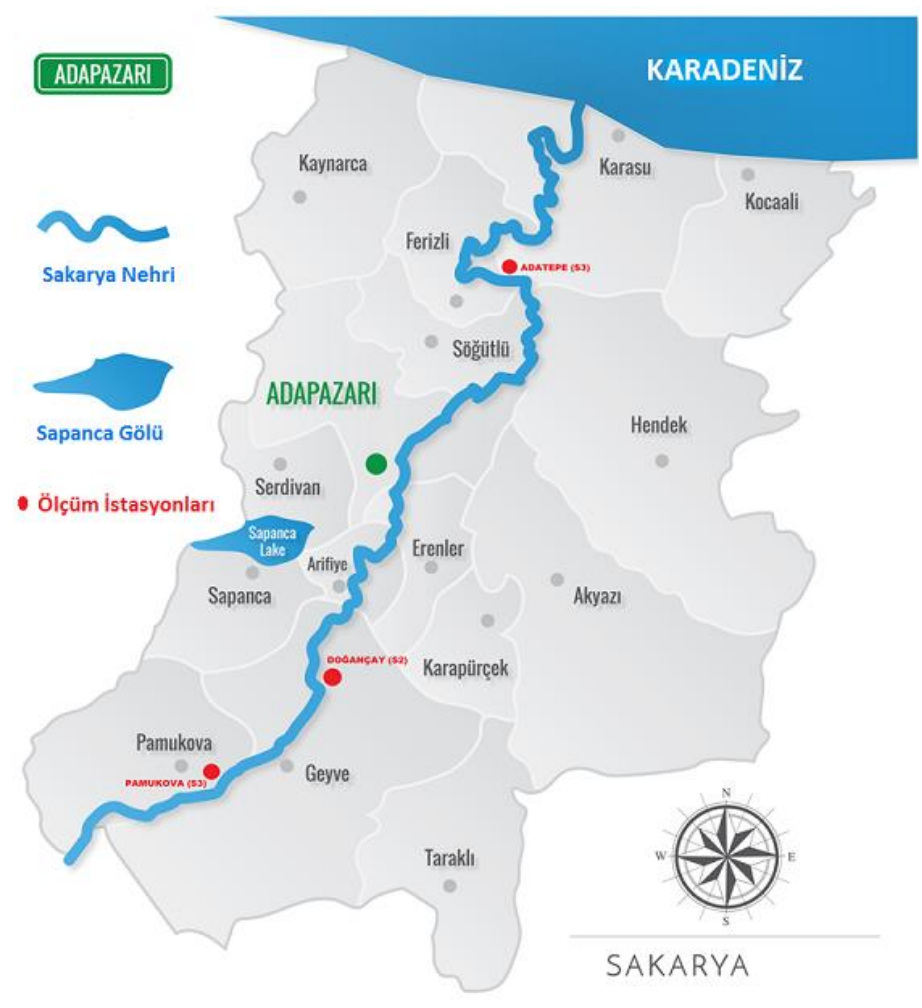

Şekil 1: Aşağı Sakarya Nehri üzerindeki ölçüm istasyonları

Tablo 1: Sulama Suyu Değerlendirme Kriterleri

\begin{tabular}{|c|c|c|}
\hline $\begin{array}{l}\text { Sodyum Yüzdesi (\%Na) } \\
\text { (Güngör 2010; Wilcox 1955) }\end{array}$ & $N a \%=\left(\frac{N a^{+}+K^{+}}{C a^{+2}+M g^{+2}+N a^{+}+K^{+}}\right)$ & $\begin{array}{c}\text { <20 Mükemmel } \\
\text { 20-40 İyi } \\
\text { 40-60 İzin verilebilir } \\
\text { 60-80 Şüpheli } \\
>80 \text { Uygun değil } \\
\end{array}$ \\
\hline $\begin{array}{l}\text { Sodyum Adsorpsiyon Oranı (SAR) } \\
\text { (Richards 1954; Mirabbasi vd. 2008) }\end{array}$ & $S A R=\frac{N a^{+}}{\sqrt{\frac{C a^{+2}+M g^{+2}}{2}}}$ & $\begin{array}{c}<20 \text { Mükemmel } \\
20-40 \text { iyi } \\
\text { 40-60 İzin verilebilir } \\
\text { 60-80 Şüpheli } \\
>80 \text { Uygun değil }\end{array}$ \\
\hline $\begin{array}{c}\text { Magnezyum Oranı (MR) } \\
\text { (Raghunath 1987; Shafiq ve Saleem } \\
\text { 2013) }\end{array}$ & $\mathrm{MR}=\frac{M g^{+2} * 100}{C a^{+2}+M g^{+2}}$ & $\begin{array}{c}<50 \text { Uygun } \\
>50 \text { Uygun değil }\end{array}$ \\
\hline $\begin{array}{c}\text { Potansiyel Tuzluluk (PS) } \\
\text { (Doneen 1964; Omotoso ve Ojo 2012) }\end{array}$ & $P S=C l^{-}+0,5 S_{4}^{-2}$ & $\begin{aligned} &<3 \text { Uygun } \\
&> 3 \text { Uygun değil } \\
&\end{aligned}$ \\
\hline $\begin{array}{c}\text { Kelly İndeksi } \\
\text { (Kelly 1963; Ibraheem ve Khan 2017) }\end{array}$ & $K I=\frac{N a^{+}}{C a^{+2}+M g^{+2}}$ & $\begin{array}{c}<1 \text { Uygun } \\
>1 \text { Uygun değil }\end{array}$ \\
\hline Toplam Sertlik (mg/L) & TS & $\begin{array}{c}60 \text { Yumuşak } \\
60-120 \text { Orta sert } \\
120-180 \text { Sert } \\
>180 \text { Çok sert } \\
\end{array}$ \\
\hline Elektriksel İletkenlik $(\mu \mathrm{S} / \mathrm{cm})$ & Eİ & $\begin{array}{c}\text { 250-750 İyi } \\
\text { 750-2000 İzin verilebilir } \\
\text { 2000-3000 Şüpheli } \\
>3000 \text { Uygun değil } \\
\end{array}$ \\
\hline
\end{tabular}




\section{Sonuçlar}

Her ne kadar toprak özellikleri ve iklimsel şartlar önemli olsa da öncelikli olarak sulu tarım için kullanılacak suyun içeriğinin bitki gelişimine önemli derecede etkisi olduğu bilinmektedir. Yüksek miktarda çözünmüş iyonlar içeren sulama suları tarımsal toprakların yapısını ve dolayısıyla bitkilerin gelişimini negatif olarak etkileyerek üretimi sınırlandırmaktadır. Bu amaçla, sulama suyu kalitesini ve uygunluğunu belirlemek için Sakarya Nehrinin Aşağı Sakarya bölümünde DSİ tarafından izlenen 3 istasyona ait veriler yağışlı ve kurak dönem olarak ayrılmıştır. Schoeller diyagramı, Sodyum Adsorbsiyon Oranı (SAR), Elektriksel İletkenlik (Eİ), Sodyum Yüzdesi (\%Na), Magnezyum Oranı (MR), Kelley İndeksi (KI) ve Potansiyel Tuzluluk (PS) gibi indekslerle sulama suyu açısından değerlendirilmiştir.

Schoeller yarı logaritmik diyagramı suların anyon katyon içeriklerine daha ayrıntılı bir ifade ile klorür, sülfat, sodyum, potasyum, kalsiyum ve magnezyum miktarlarına göre değerlendirme amacı ile kullanılan bir diyagramdır. Her bir iyonun meq/L değerleri logaritmik olarak oluşturulan düşey eksenlere girilerek birleştirilir. Sulama suyu uygunluğu açısından değerlendirdiğimiz Aşağı Sakarya Nehri suyu yağışlı ve kurak dönem için istasyonlara göre Schoeller Diyagramı ile de değerlendirilmiş ve sonuçlar Şekil 2'de verilmiştir. İncelenen parametrelerin yağışlı dönemde hesaplanan değerlerinin kurak dönemdeki değerlerine göre daha düşük olduğu tespit edilmiştir. Yağışlı dönemde katyonlar İS1'de $\mathrm{Ca}>\mathrm{Na}>\mathrm{Mg}$ $>\mathrm{K}$, İS2 ve İS3'de $\mathrm{Ca}>\mathrm{Mg}>\mathrm{Na}>\mathrm{K}$; anyonlar ve $\mathrm{SO}_{4}>\mathrm{Cl}$ şeklindedir. Kurak dönemde tüm istasyonlarda katyonlar $\mathrm{Ca}>$ $\mathrm{Mg}>\mathrm{Na}>\mathrm{K}$; anyonlar ve $\mathrm{SO}_{4}>\mathrm{Cl}$ şeklinde dizilim göstermişlerdir. Klorür değerleri 15meq/L'den küçük olduğu için su normal klorürlü su sınıfına, sülfat değerleri de 6 meq/L'den küçük olduğu için normal sülfatlı su sınıfına girmektedir ve bölgedeki karbonatlı kayaçlardan gelen su içeriğine işaret etmektedir (Erdoğan 2013)

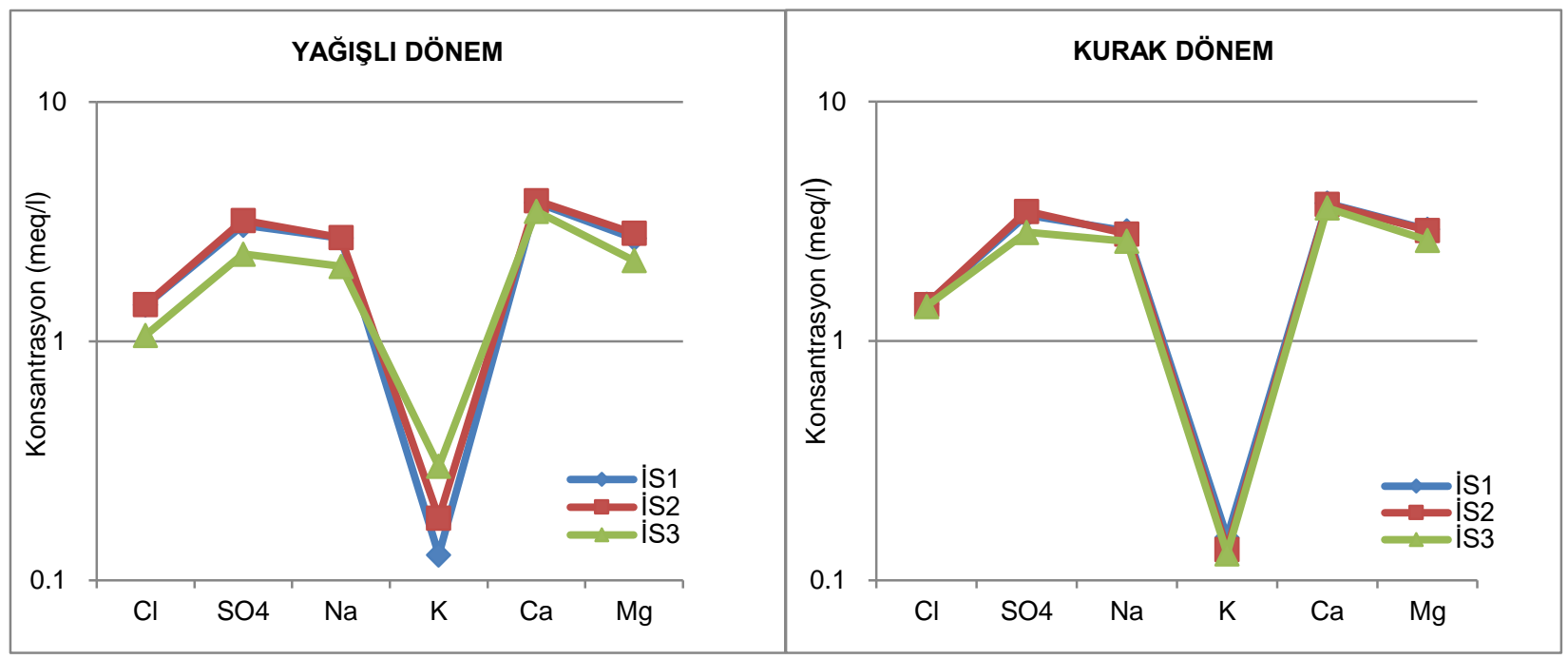

Şekil 2: Istasyonlara göre parametrelerin yarı logaritmik (Schoeller) diyagramı

\subsection{Sodyum Adsorbsiyon Oranı (SAR)}

SAR, sulama suyunun topraktaki katyon değişim reaksiyonlarına girme eğilimini belirleyen bir yaklaşımdır. SAR'ın yüksek değerleri, emilen kalsiyum ve magnezyumun yerini alan sodyumun, toprak yapısına nihai olarak zarar veren bir tehlike olduğunu ifade etmektedir (Hem 1985).

Her bir istasyon için yağışlı ve kurak döneme göre SAR değerleri ayrı ayrı hesaplanmıştır. SAR değerleri yağışlı dönem için İS1'de 0,89-1,94, İS2'de 0,19-2,01 ve İS3'de 0,58-2,02; kurak dönem için sirasıyla 0,87-2,10, 0,78-2,07, 0,78-2,76 değerleri arasındadır. Bu değerlere göre tüm istasyonlar için su sınıfı SAR açısından mükemmel sınıfı ifade etmektedir (Naseem vd. 2010; Bouaroudj vd. 2019). Bu da Aşağı Sakarya Nehri’nin sulama suyu olarak kullanılmasının sodyum içeriği açısından bir tehlike taşımadığını göstermektedir. Şekil 3'de yağışlı ve kurak dönem için ABD Tuzluluk Diyagramına (Richards 1954) göre Sodyum tehlikesi-tuzluluk tehlikesi arasında oluşturulmuş grafikler verilmektedir. Bu değerlendirmeye göre yağışlı ve kurak dönem için ölçülen değerler orta tuzlu- az sodyumlu su (C2-S1) ve yüksek tuzluaz sodyumlu su (C3-S1) sınıfını işaret etmektedir. Bu tip sular da sulamaya uygun olarak sınıflandırılmaktadır. 


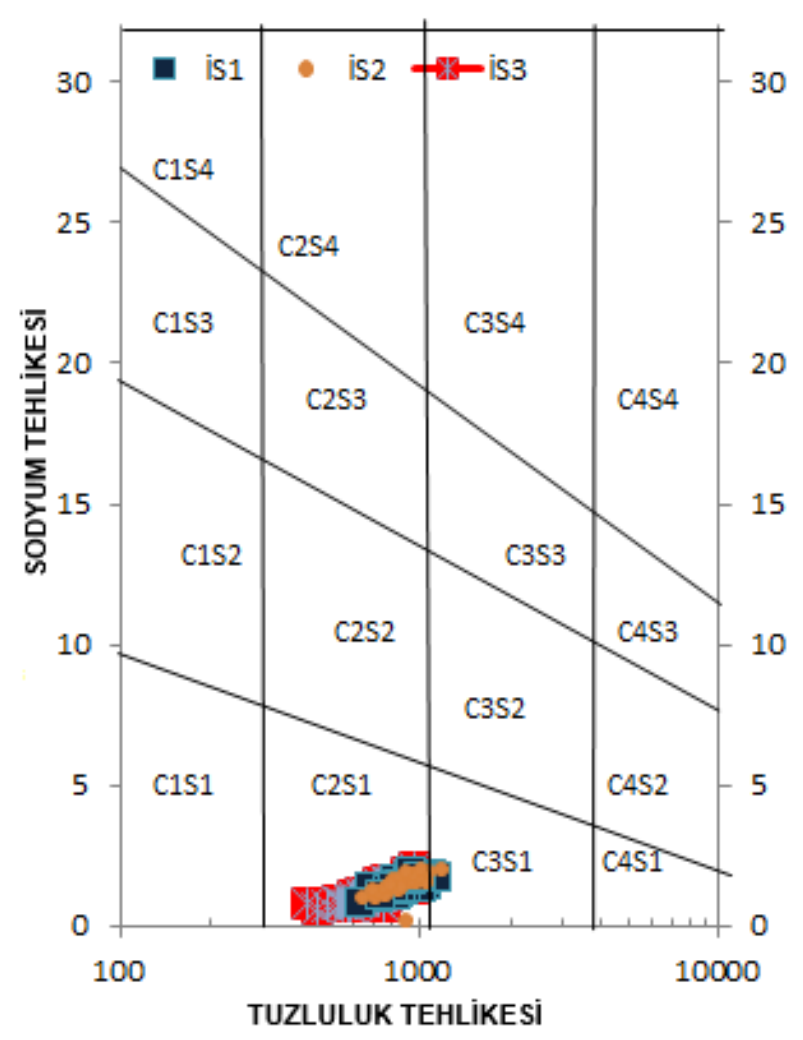

a)Yağışı Dönem

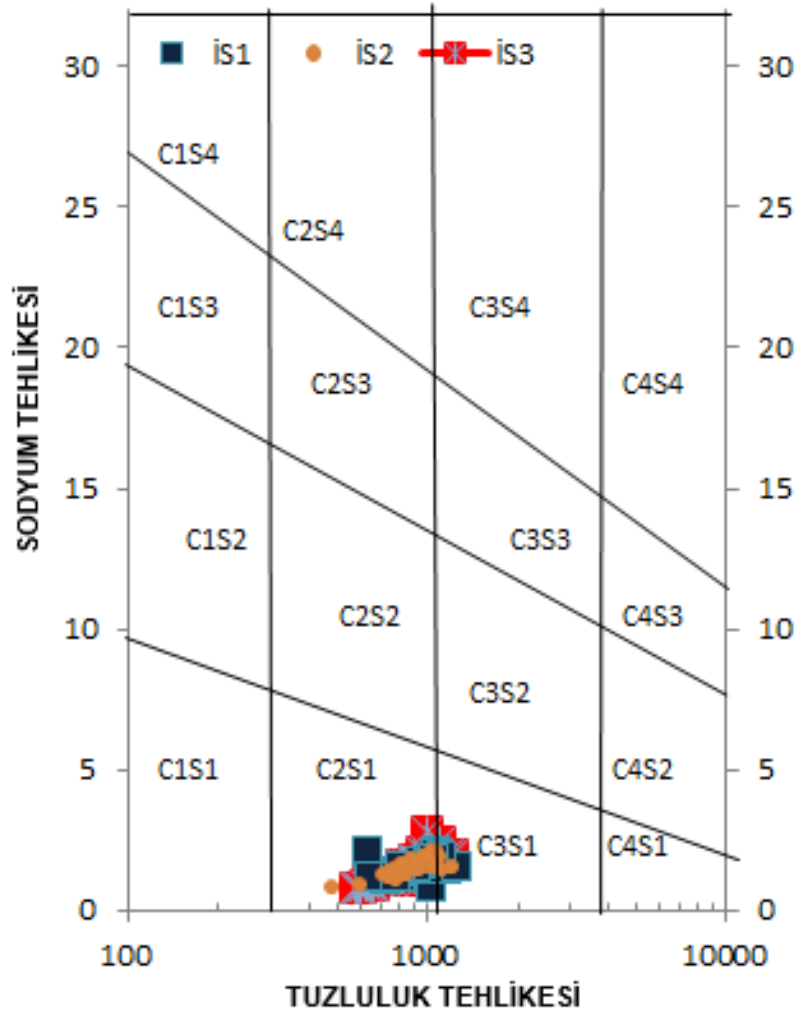

b) Kurak Dönem

Şekil 3: Tuzluluk ve sodyum tehlikesine bağlı sınıflandırma (ABD Tuzluluk Diyagramı)

Suların tuzluluk ve sodyum miktarlarına göre sınıflandırılmasında C ve S harfleri ile sırasıyla tuzluluk ve sodyum miktarları sembolize edilmekte, rakamlar ise 1'den 4'e doğru artışı ifade etmektedir. C1 az tuzlu su, C4 ise çok yüksek tuzlu su sınıfı olup sulama suyu için uygun değildir. C2 sınıfı ise orta tuzlulukta su olup orta derecede suya ihtiyaç gösteren bitkiler için kullanılabilmektedir. Sodyum sınıflandırmasında ise S1 az sodyumlu suyu ifade eder ve sodyuma karşı duyarlı olan bitkiler dışında her türlü tarım için uygundur şeklinde yorumlanmaktadır (Güngör 2010)

\subsection{Elektriksel İletkenlik (EC)}

Ürün verimliliğine ilişkin en etkili su kalitesi göstergesi, elektriksel iletkenlik (EC) ile ölçülen su tuzluluğu tehlikesidir. Yüksek EC içeren bir suyun ürün verimliliğine olan etkisi, bitkinin su için toprak çözeltisinde iyonlarla rekabet edememesidir. EC ne kadar yüksekse, toprak 1slak görünmesine rağmen bitkiler için o kadar daha az su mevcuttur (Joshi vd. 2009).

İstasyonlar için yağışlı ve kurak dönemdeki EC değerlerine göre yağışlı dönem için İS1'de 623-1110 mohm/cm, İS2'de 641-1178 mohm/cm ve İS3'de 416-993 mohm/cm; kurak dönem için sirasıyla 623-1223 mohm/cm, 479-1208 $\mathrm{mohm} / \mathrm{cm}, 575-1200 \mathrm{mohm} / \mathrm{cm}$ değerleri arasındadır. Tüm istasyonlardaki örnekler için su sınıfı EC açısından iyi ve izin verilebilir düzeydedir (Richards 1954). Bu da Aşağı Sakarya Nehri’nin sulama suyu olarak kullanılmasının tuzluluk tehlikesi yaratmadığını ifade etmektedir.

\subsection{Sodyum Yüzdesi (\%Na)}

Sodyum yüzdesi sodyum tehlikesini incelemek için kullanılan diğer bir yaklaşımdır. Sulama amaçlı olarak yüksek sodyum yüzdeli su kullanılması bitki büyümesini hızlandırır. Genellikle sodyum yüzdesi değerleri düşük olduğunda küçük sorunlar ortaya çıkar. Yüksek olduğunda ise azaltılmış geçirgenlik meydana gelecektir. Daha ince toprak dokusu ve organik madde içeriği ne kadar büyükse, sodyumun su infiltrasyonu ve havalandırması üzerindeki etkisi de o kadar büyük olacaktır (Joshi vd. 2009).

Çalışmada izlenen istasyonlar açısından hesaplandığında yağışlı ve kurak dönem için değerlerin \%99'unun sodyum yüzdesi açısından \%20-\%40 arasında değiştiği belirlenmiştir (Şekil 4). Bu durum da sodyum yüzdesi açısından sulama suyu olarak kullanılabilirliğinin iyi düzeyde olduğunu göstermektedir (Wilcox 1955). 


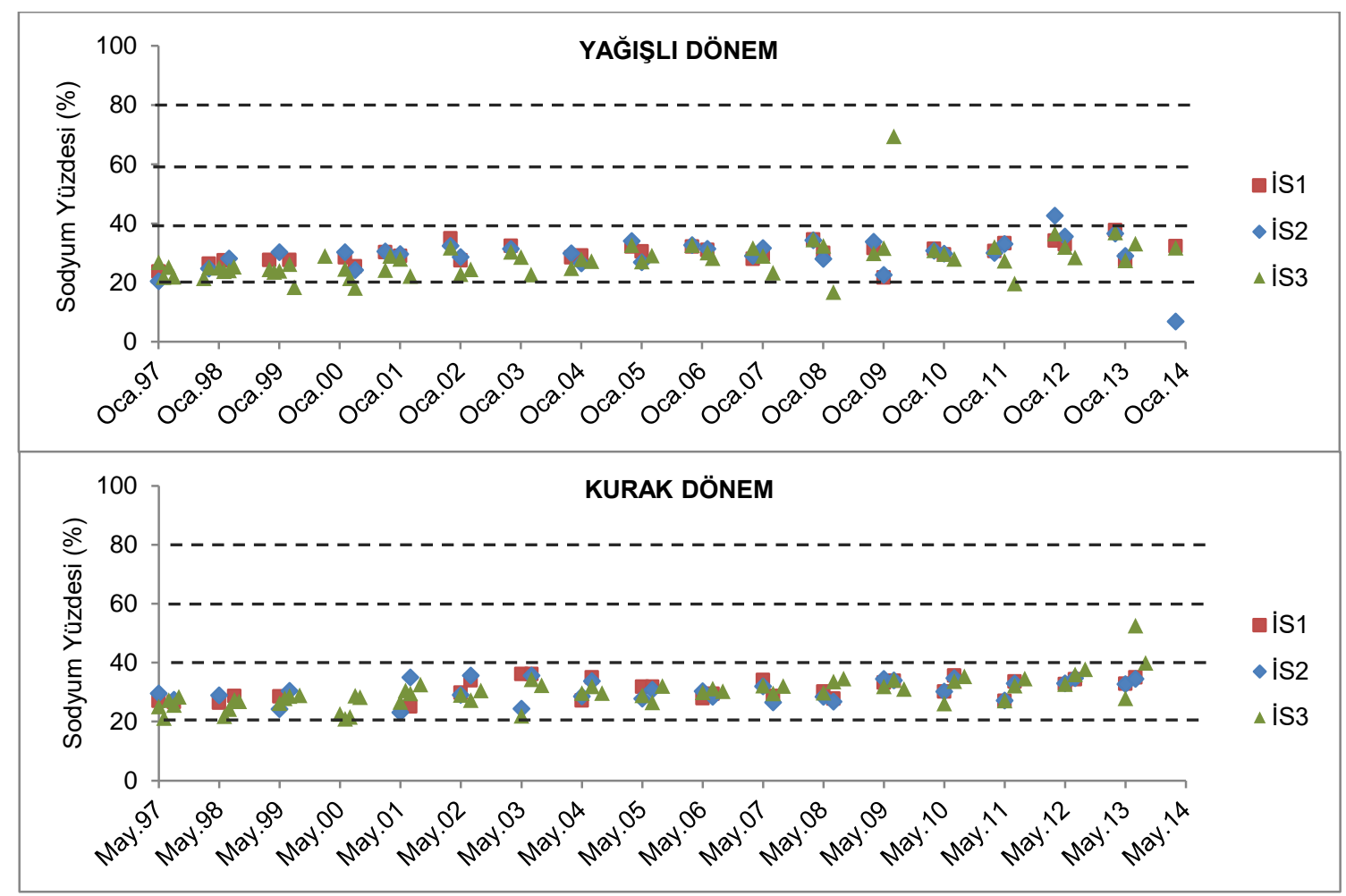

Şekil 4: Yağışlı ve Kurak dönem için Sodyum yüzdeleri

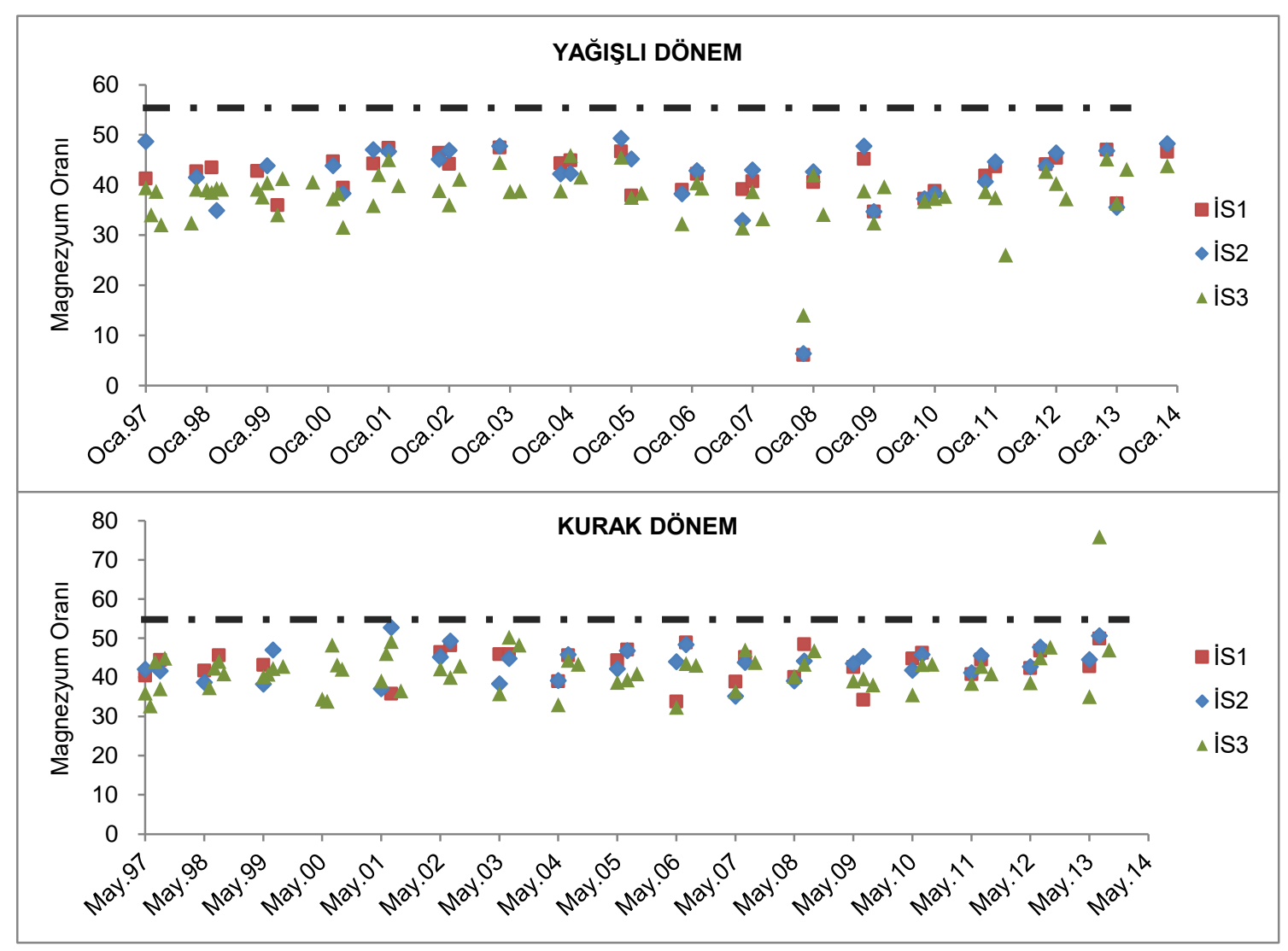

Şekil 5: Yağışı ve Kurak dönem için MR oranları 


\subsection{Magnezyum Oranı (MR)}

Magnezyum oranı, sulama için suyunun kalitesini belirlemede en önemli kalitatif kriterlerden biri olarak kabul edilmektedir. Magnezyum suda gerekli olduğundan daha fazla ise, toprak daha tuzlu hale geldikçe mahsul verimi üzerinde olumsuz bir etki olacaktır (Omotoso ve Ojo 2012).

İstasyonlar için yağışlı ve kurak döneme göre MR değerleri hesapların \%99'unda genellikle 30-50 arasında değişsmektedir (Şekil 5). Elde edilen sonuçların hemen hemen tamamı $<50$ olduğu için MR açısından uygun sınıfı ifade etmektedir (Raghunath 1987). Bu da Aşağı Sakarya Nehri'nin MR açısından sulama suyu olarak kullanıma uygun olduğunu göstermektedir.

\subsection{Kelley İndeksi (KI)}

Kelly Indeksi, Ca ve Mg ile ölçülen Na seviyesine göre sulama suyu kalitesini değerlendirmek için ortaya çıkarılmış önemli bir parametredir. Kelley indeksi oranı <1 olan sular sulama için uygundur (Kelly 1963; Ibraheem ve Khan 2017). Çalışma alanı içinde elde edilen ölçümlerle hesaplanan KI değerleri yağışlı ve kurak dönem için $<1$ olarak belirlenmiştir (Şekil 6). KI değerlerinin 1'den küçük olması, izlenen tüm istasyonlardaki suların iyi kaliteli ve sulama amaçlı kullanım için uygun olduğunu göstermektedir.

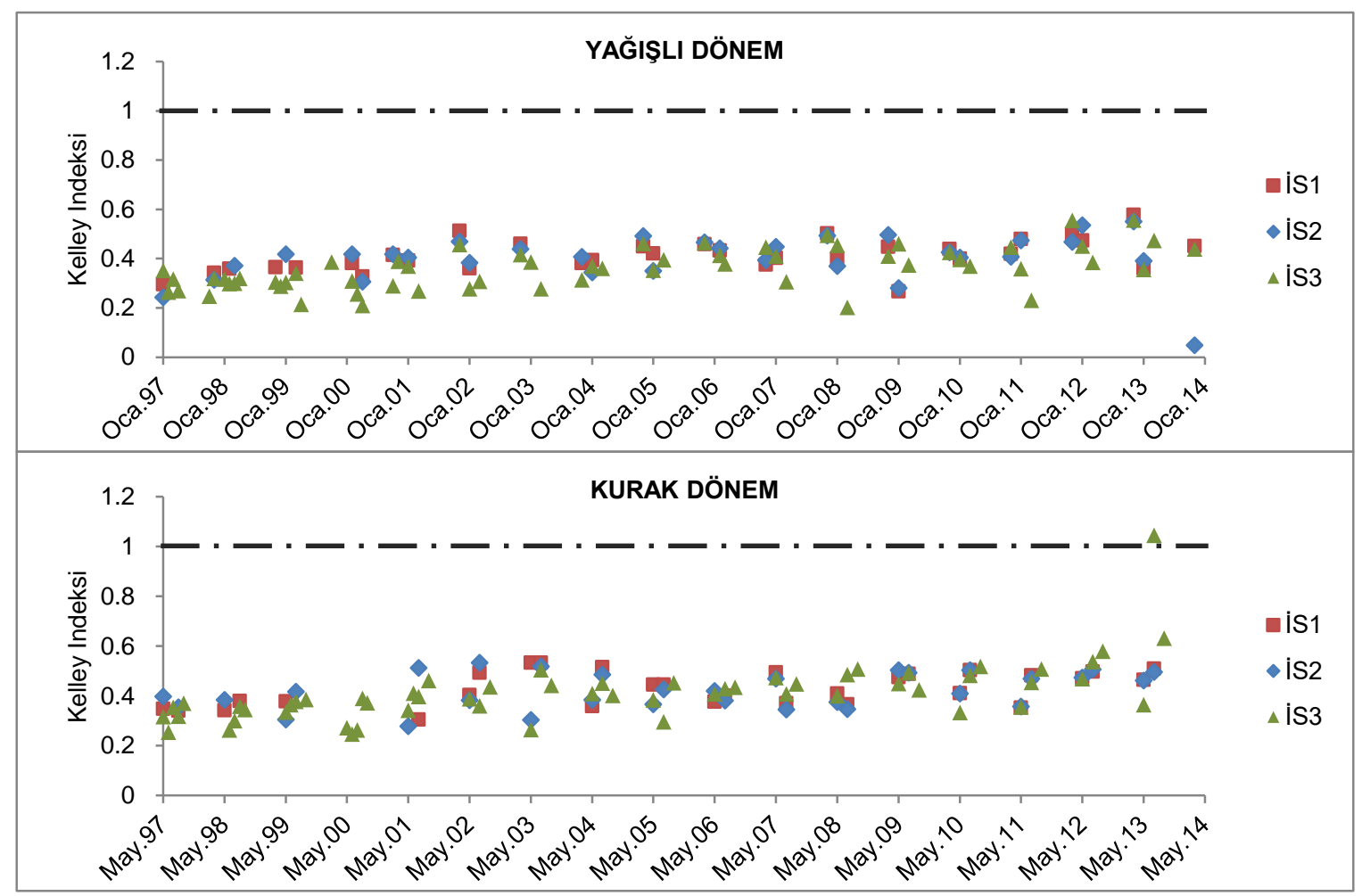

Şekil 6: Yağışlı ve Kurak dönem için Kelley Indeksi

\subsection{Potansiyel Tuzluluk (PS)}

Potansiyel tuzluluk, sulama suyu kalitesinin belirlenmesinde faydalanılan başka bir parametredir. PS değerinin 3 meq/l' den düşük olması sulama amaçlı kullanım için suyun uygun olduğunu göstermektedir (Doneen 1964; Omotoso ve Ojo 2012).

İstasyonlar için yağışlı ve kurak döneme göre hesaplanan PS değerleri, yağışlı dönem verilerinin yaklaşık \%75'nin, kurak dönem verilerinin de yaklaşık \%50'sinin sulama suyu açısından uygun olduğunu göstermektedir (Şekil 7).

\subsection{Toplam Sertlik (TH)}

Su sertliğinin belirlenmesi, evsel, tarımsal ve endüstriyel kullanımlar için suyun kalitesini değerlendirmede faydalı bir yaklaşımdır. Suyun sertliği genellikle kalsiyum ve magnezyumdan kaynaklanır (Bhat vd. 2016). 
İstasyonlar için alınan örneklerde sınıflandırmaya göre, çok sert tipte \% 99'dan fazla örnek bulunmuştur (Şekil 8). Toplam sertlik bazında suyun sınıflandırılması, örneklerinin çoğunun çok sert su tipinde olduğunu göstermektedir (Dufor ve Becker 1962).

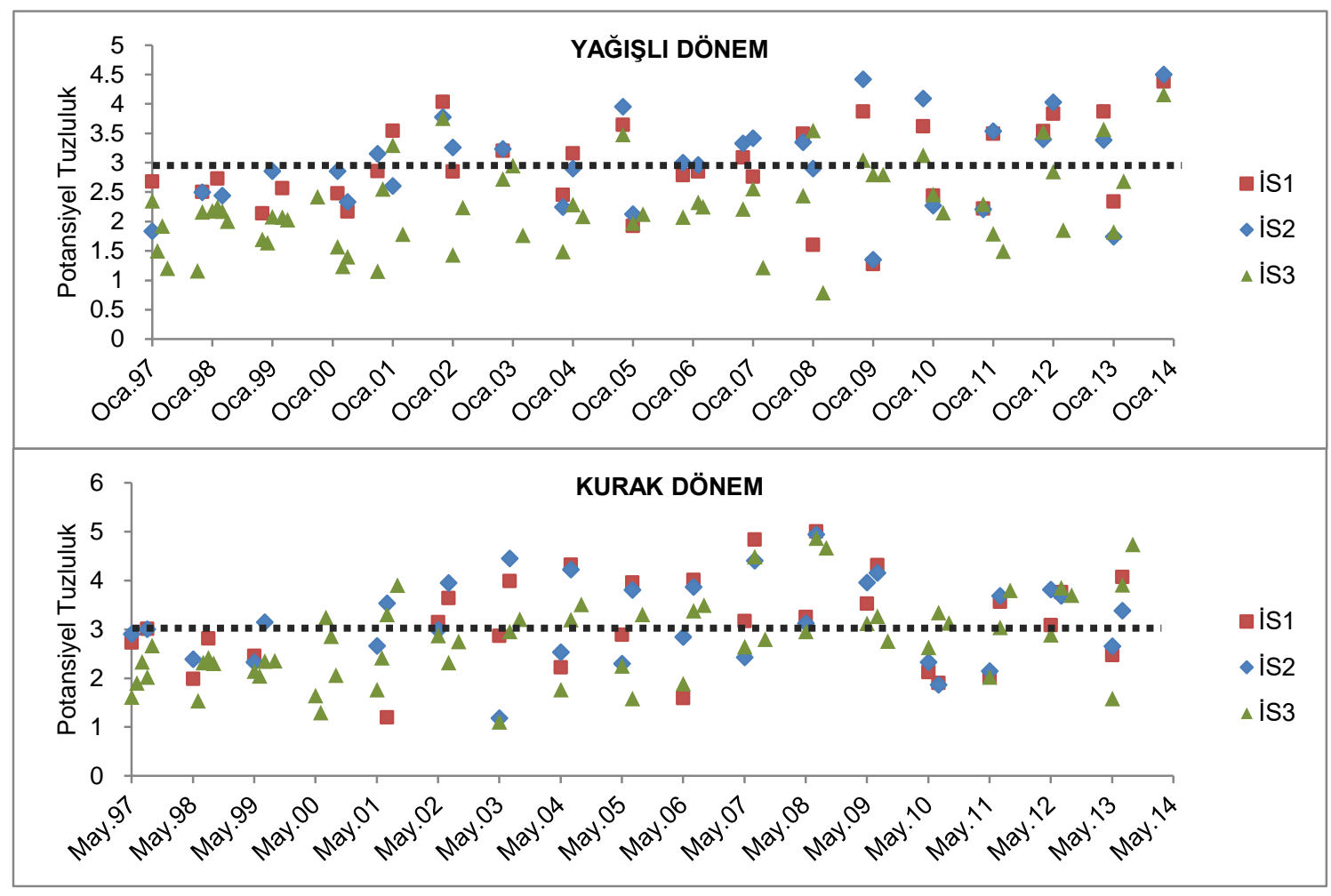

Şekil 7: Yağışlı ve Kurak dönem için Potansiyel Tuzluluk

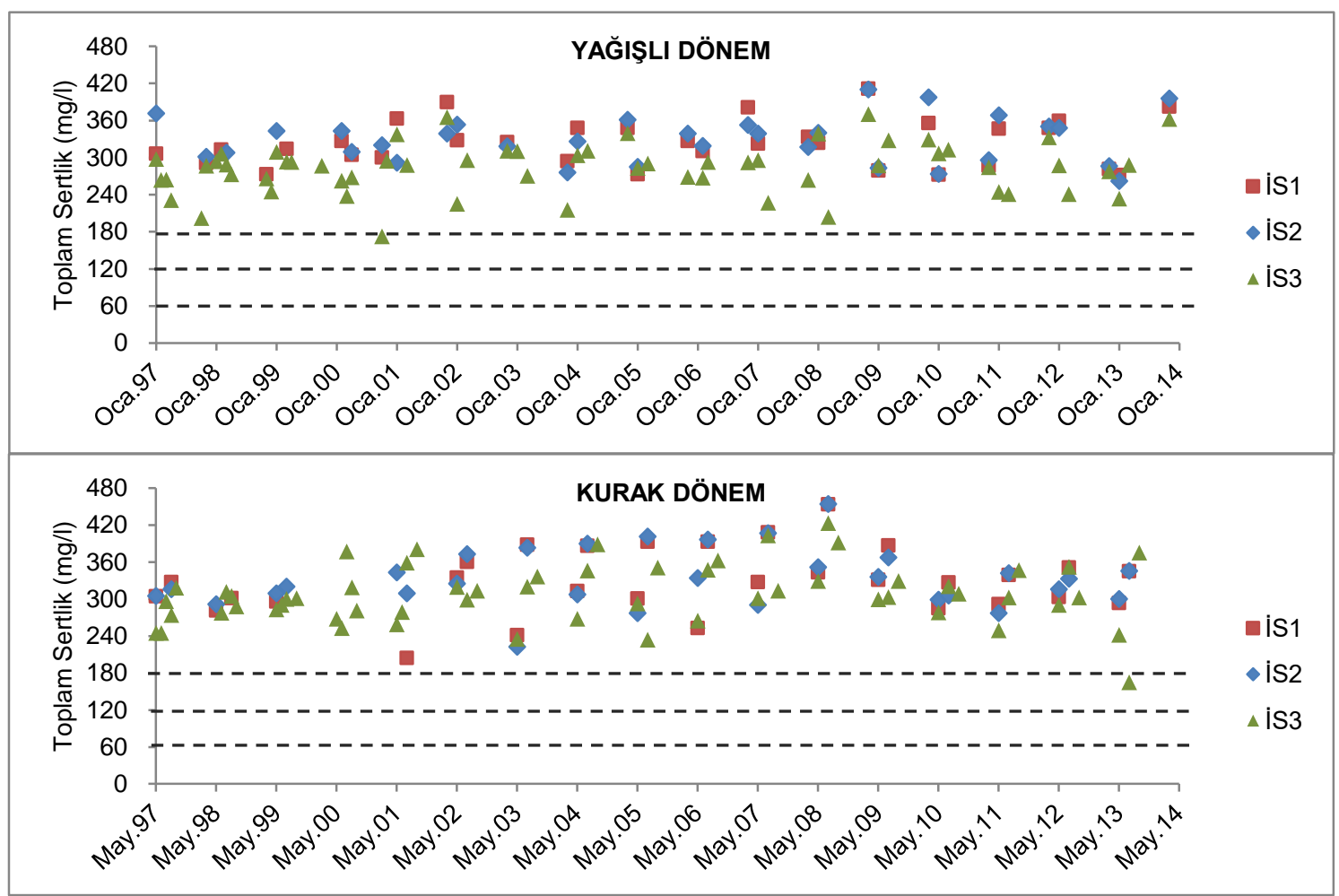

Şekil 8: Yağışı ve Kurak dönem için Toplam Sertlik 


\section{Tartışma ve Öneriler}

Aşağı Sakarya Nehri'nde farklı istasyonlara ait verilerde sulama suyunun farklı fiziko-kimyasal özellikleri, sulama için belirlenen kalite kriterleri ile değerlendirilmiştir. Yapılan değerlendirme neticesinde, tüm istasyonlar için sulama suyu SAR açısından mükemmel, EC, sodyum yüzdesi, MR ve KI açısından iyi, uygun ve izin verilebilir olarak belirlenmiştir. ABD Tuzluluk Diyagramına göre yağışlı ve kurak dönem için ölçülen değerler orta tuzlu- az sodyumlu su ve yüksek tuzlu- az sodyumlu su sınıfını işaret etmektedir. Bu tip sular da sulamaya uygun olarak sınıflandırılmaktadır. Schoeller diyagramına göre yağışlı dönemde katyonlar İS1'de $\mathrm{Ca}>\mathrm{Na}>\mathrm{Mg}>\mathrm{K}$, İS2 ve İS3'de $\mathrm{Ca}>\mathrm{Mg}>\mathrm{Na}>\mathrm{K}$; anyonlar ve $\mathrm{SO}_{4}>\mathrm{Cl}$ şeklindedir. Kurak dönemde tüm istasyonlarda katyonlar $\mathrm{Ca}>\mathrm{Mg}>\mathrm{Na}>\mathrm{K}$; anyonlar ve $\mathrm{SO}_{4}>\mathrm{Cl}$ şeklinde dizilim göstermişlerdir. Klorür ve sülfat parametrelerine göre de normal klorürlü su ve normal sülfatlı su sinıfına girmektedir ve bu durum da bölgedeki karbonatlı kayaçlardan gelen su içeriğine işaret etmektedir. Bahsedilen özellikleri ile Aşağı Sakarya Havzası su kalitesi sulama açısından uygun nitelikte su olarak belirlenmiştir. Ancak Toplam sertliğe göre örneklerin çoğu sulama suyu bakımından çok sert su tipindedir. Sulardaki sertliğin yüksek olması, bölgenin Sakarya Nehri ve kollarıyla birlikte oluşmuş alüvyon zemin üzerinde olmasından kaynaklanmaktadır. PS açısından da, yağışlı dönem verilerinin yaklaşık \%75'nin, kurak dönem verilerinin de yaklaşık \%50'sinin sulama suyu açısından uygun olduğu sonucuna varılmıştır. Potansiyel tuzlanmanın özellikle bölgede yapılan tarım uygulamalarından, evsel ve endüstriyel deşarjlardan kaynaklandığı ifade edilebilir. Bu nedenle havzada yapılan tarım uygulamaları ve sulama yöntemleri ile nehre yapılan atık su deşarjları kontrol altına alınmalıdır. Ülkemizde henüz sulama sularının sınıflandırılması ile ilgili yönetmeliklerin tamamlanıp yürürlüğe girmemesi de sulama maksadıyla kullanılan su kaynaklarının değerlendirilmesini zorlaştırmaktadır. Her ne kadar bu çalışmada olduğu gibi var olan uluslararası parametreler değerlendirme için kullanılsa da ülkemiz için de su kaynaklarının kalitesinin arttırılabilmesi ve kullanılmış suların yeniden kullanımının sağlanması için en kısa zamanda gerekli çalışmaların yapılması ve ulusal standartlarımızın belirlenmesi gerekmektedir.

\section{Teşekkür}

Çalışmaya ait verileri elde etmemizi sağlayan Devlet Su İşleri Genel Müdürlüğü Etüt Plan Daire Başkanlığı’’na teşekkür ederiz.

\section{Kaynaklar}

Asri F.Ö., Demirtaş E.I., Ari N., Arpacioğlu A.E., Özkan C.F., (2010), Antalya-Serik yöresi seralarında kullanılan sulama sularının kalitelerinin belirlenmesi, Akdeniz Üniversitesi Ziraat Fakültesi Dergisi, 23(2), 145-150.

Bhat M.A., Grewal M.S., Rajpaul R., Wani S.A., Dar E.A., (2016), Assessment of groundwater quality for Irrigation purposes using chemical indices, Indian Journal of Ecology, 43(2), 574-579.

Bouaroudj S., Menad A., Bounamous A., Chenchouni H., (2019), Assessment of water quality at the largest dam in Algeria (Beni Haroun Dam) and effects of irrigation on soil characteristics of agricultural lands, Chemosphere, 219, 76-88.

Doneen L.D., (1964), Notes on water quality in agriculture, Department of Water Science and Engineering, University of California, Davis.

Dufor C.N., Becker E., (1962), Public water supplies of the 100 largest cities in the United States, U.S. Geological Survey WaterSupply Paper 1812, https://pubs.usgs.gov/wsp/1812/report.pdf, [Erişim 20 Şubat 2019].

Emre T., Sözbilir H., (2005), Kütahya Ovası 'ndaki yüzey ve yer altı sularının sulama suyu kalitesi açısından incelenmesi, MTA Dergisi, $131,1-19$.

Etteieb S., Cherif S., Tarhouni J., (2015), Hydrochemical assessment of water quality for irrigation: a case study of the Medjerda River in Tunisia, Applied Water Science, 1-12.

Güngör T., (2010), Oğulbey (Gölbaşı) akiferlerinin yeraltı suyu kalitesinin incelenmesi, Yüksek Lisans Tezi, Gazi Üniversitesi, Ankara.

Hem D., (1985), Study and Interpretation the Chemical of Natural of Characteristics Water, Geological Survey Water-Supply Paper 2254, https://pubs.usgs.gov/wsp/wsp2254/pdf/wsp2254a.pdf, [Erişim 13 Kasim 2018].

Ibraheem A.M., Khan S.M.M.N., (2017), Suitability Assessment of Groundwater for Irrigation Purpose in Veppanthattai Block , Perambalur District, Tamil Nadu, World of Scientific News, 81(3), 81-93.

Islam M.S., Shamsad K.M., (2009), Assessment of Irrigation Water Quality of Bogra, Bangladesh J. Agril. Res., 34(4), 597-608.

Joshi D.M., Kumar A., Agrawal N., (2009), Assessment of the irrigation water quality of river Ganga in Haridwar district, Rasayan Journal of Chemistry, 2(2), 285-292.

Kelly W.P., (1963), Use of Saline Irrigation Water, Soil Science, 95(6), 385-391.

Erdoğan M., (2013), Burdur-Ağlasun Havzasının Hidrojeoloji İncelemesi, Yüksek Lisans Tezi,İstanbul Teknik Üniversitesi, İstanbul, Türkiye.

Mirabbasi R., Mazloumzadeh S.M., Rahnama M.B., (2008), Evaluation of Irrigation Water Quality Using Fuzzy Logic, Res. J. Environ. Sci, 2(5), 340-352.

Muthanna M.N., (2011), Quality Assessment of Tigris River by using Water Quality Index for Irrigation Purpose, European Journal of Scientific Research, 57(1), 15-28.

Naseem S., Hamza S., Bashir E., (2010), Groundwater Geochemistry of Winder Agricultural Farms, Balochistan, Pakistan and Assessment for Irrigation Water Quality, European Water, 31, 21-32. 
Omotoso O.A., Ojo O.J., (2012), Assessment of quality of river Niger floodplain water at Jebba, central Nigeria : implications for irrigation, Water Utility Journal, 4, 13-24.

Raghunath I.I.M., (1987), Groundwater, Second edt., New Delhi, India: Wiley Eastern Ltd.

Richards L.A. (1954), Diagnosis and Improvement of Saline and Alkali Soils. (L. A. Richards, Ed.), Washington, D.C.: United States Department of Agriculture.

Shafiq M., Saleem M., (2013), Quality assessment of ground water for irrigation in District Jhang, Journal of Agricultural Research (Lahore), 51(2), 149-160.

URL-1, (2016), Sakarya İli 2015 Yılı Çevre Durum Raporu, T.C. Sakarya Valiliği Çevre ve Şehircilik İl Müdürlüğü, Sakarya, https://webdosya.csb.gov.tr/db/ced/editordosya/Sakarya2015.pdf, [Erişim 01 Mart 2018].

Wilcox L.V, (1955), Classification and Use of Irrigation Waters, Washington, D.C. United States Department of Agriculture, (969):119. 